\title{
Transverse myelopathy in systemic lupus erythematosus: an analysis of 14 cases and review of the literature
}

\author{
Birgit Kovacs, Thomas L Lafferty, Lawrence H Brent, Raphael J DeHoratius
}

\begin{abstract}
Objective-To give a comprehensive review of transverse myelopathy (TM), a rare but serious condition reported in $1-2 \%$ of patients with systemic lupus erythematosus (SLE).

Methods-14 patients with SLE and TM were evaluated and 91 additional cases published in the English and German literature reviewed.

Results-TM presented either as the initial manifestation or within five years of the diagnosis of SLE. Most patients presented with a detectable sensory deficit at the thoracic level. In our 14 patients, $22 \%$ of the patients showed complete neurological recovery, whereas in the total patient population of 105 (our cases plus those reviewed in the literature), complete recovery was observed in $50 \%$, partial recovery in $29 \%$ and no improvement or deterioration in $21 \%$. Treatment with intravenous methylprednisolone followed by cyclophosphamide seemed to be most effective. Seventy per cent of the total patient population had abnormal magnetic resonance imaging findings. In our group of 14 patients, those with higher disease activity (measured by the SLAM) at onset of TM were treated more aggressively (for example, with plasmapheresis and intravenous pulse cyclophosphamide). TM in our patients was associated with antiphospholipid antibodies in $43 \%$ of the cases as compared with $64 \%$ of the total patient population. Optic neuritis occurred in $48 \%$ of the total patient population with SLE and TM, suggesting an association.

Conclusions-TM in SLE is a poorly understood entity. Outcome might be more favourable than previously suggested. There is an association of TM with antiphospholipid antibodies in SLE patients. Treatment including intravenous cyclophosphamide may improve the final outcome. This report emphasises the need for multicentre trials to establish guidelines for optimal treatment. (Ann Rheum Dis 2000;59:120-124)
\end{abstract}

Systemic lupus erythematosus (SLE) is a multisystem autoimmune disease with protean manifestations. Neuropsychiatric manifestations are present in up to $60 \%$ of patients with SLE with psychosis, seizures, headaches and cerebrovascular accidents (CVA) being most common. ${ }^{12}$ Transverse myelopathy (TM), a process involving the entire thickness of the spinal cord, is a rare event with an estimated incidence of $1.34 /$ million in the general population. ${ }^{3}$ Potential causes of TM include multiple sclerosis, viral infections (herpes simplex, influenza, Epstein-Barr virus), immunisations (smallpox, influenza) and intoxication (baclofen, penicillins, lead). The usually dramatic presentation with rapidly progressive symptoms involving motor, sensory and autonomic functions including loss of bowel and bladder control makes TM a medical emergency. The pathophysiological mechanism of TM in SLE is uncertain, although vasculitis and arterial thrombosis resulting in ischaemic cord necrosis have been suggested. ${ }^{4}$ The fact that TM in SLE is rare, having been reported in only $1-2 \%$ of patients, ${ }^{1}$ renders the study of this serious entity difficult. We performed a retrospective review of 14 patients with SLE and TM who were seen at our medical centres and also provided a concise review of the literature.

\section{Methods}

Out of a total population of approximately 600 patients with SLE seen in two academic institutions, 14 patients with TM were identified. All patients met the diagnostic criteria for SLE as proposed in the American College of Rheumatology revised classification criteria for SLE. ${ }^{5}$ TM was diagnosed by clinical manifestation indicative of a spinal cord lesion with associated sensory or motor deficits, bladder/bowel dysfunction, or any combination thereof.

Patient data were collected from inpatient and outpatient medical records at Albert Einstein Medical Center and Thomas Jefferson University Hospital. It included clinical manifestations of SLE and TM, clinical course and laboratory data such as serology, antiphospholipid antibodies and magnetic resonance imaging (MRI) findings. Disease activity was determined using the Systemic Lupus Activity Measure (SLAM). ${ }^{6}$ Patients were divided into three treatment groups: group A received intravenous methylprednisolone (MP) $1 \mathrm{~g}$ daily

Table 1 Patient details

\begin{tabular}{|c|c|c|c|c|}
\hline & \multicolumn{2}{|c|}{ Our cases $(n=14)$} & \multicolumn{2}{|c|}{ Total cases $(n=98)$} \\
\hline & $\begin{array}{l}\text { Onset } \\
\text { TM }\end{array}$ & $\begin{array}{l}\text { Onset } \\
\text { SLE }\end{array}$ & $\begin{array}{l}\text { Onset } \\
\text { TM }\end{array}$ & $\begin{array}{l}\text { Onset } \\
\text { SLE }\end{array}$ \\
\hline Mean age & 42 & 39 & 33 & 32 \\
\hline Median age & 41 & 38 & 31 & 30 \\
\hline Range & $23-77$ & $19-77$ & $9-77$ & $9-77$ \\
\hline
\end{tabular}

Accepted for publication 13 October 1999 
Table 2 Clinical features of our patients

\begin{tabular}{lllll}
\hline Patient & Age/symptoms & Duration of SLE & Other neurological symptoms & Other clinical features \\
\hline 1 & 67 years/paraplegia & 5 years & Depression & Arthritis, nephritis, lymphopenia \\
2 & 52 years/pain, urinary retention & 0 years & Depression & Raynaud's \\
3 & 49 years/paresthesias, R LE paresis & 2 years & None & Arthritis, nephritis \\
4 & 41 years/paresthesias, L LE paresis & 0 years & Optic neuritis & Oral ulcers, arthritis \\
5 & 36 years/paraparesis & 0 years & Optic neuritis & Fatigue, rash, nephritis \\
6 & 23 years/paresthesias, L LE paresis & 0 years & Pseudotumour cerebri & Alopecia, arthritis, thrombocytopenia \\
7 & 58 years/paresthesias & 21 years & None & Weight loss, arthritis \\
8 & 57 years/paresthesias, paraparesis & 11 years & None & NA \\
9 & 23 years/paresthesias & 4 years & None & Nephritis \\
10 & 27 years/paresthesias, paraparesis & 2 years & Optic neuritis, seizures & Nephritis, pregnancy loss \\
11 & 25 years/paraparesis & 2 years & Psychosis, CVA & Dash, arthritis \\
12 & 77 years/paraparesis & Rearinal artery occlusion & Arthritis \\
13 & 49 years/paraparesis & 0 years & None & Arthritis \\
14 & 26 years/paresthesias & 0 years & None & \\
\end{tabular}

for three days followed by oral prednisone $(n=5)$; group B received intravenous MP $1 \mathrm{~g}$ daily for three days followed by intravenous cyclophosphamide (CP) up to $1 \mathrm{~g} / \mathrm{m}^{2}$ body surface area $(n=4)$; group $C$ received intravenous MP $1 \mathrm{~g}$ daily for three days followed by five days of plasmapheresis with four exchanges of plasma/day and intravenous CP as in group $B(n=4)$. All patients were treated with tapering doses of oral corticosteroids.

Thirty five publications of case reports and case series from the English and German literature were reviewed. These publications dated from 1972 to 1999 and included 91 cases. ${ }^{4-39}$ Demographic data as well as data on presentation, treatment and outcome were extracted from the literature. Patients in studies before 1982 were diagnosed as having SLE according to the preliminary criteria for the classification of SLE from $1972 .{ }^{40}$ In total, we report on 105 cases of TM in patients with SLE.

\section{Results}

Table 1 shows the demography of our patient population compared with the total patient population (our patients plus the patients from the literature). The age of our patient group was slightly older on average compared with the total patient population (demographic data of seven patients from the literature were not available). There were nine male patients (9\%) with TM identified in the total patient population. This is consistent with the percentage of male patients encountered in the general population of patients with SLE. In most

Table 3 Laboratory features of our patients

\begin{tabular}{llllllll}
\hline Patient & ESR & $\begin{array}{l}\text { Anti- } \\
\text { DNA }\end{array}$ & Complement & aPL & $\begin{array}{l}\text { Other } \\
\text { serology }\end{array}$ & MRI & CSF \\
\hline 1 & 20 & - & Normal & - & - & TM & NA \\
2 & 33 & + & Normal & - & - & TM & WBC 1 \\
& & & & & & Protein 134 \\
3 & 33 & + & Normal & - & - & TM & NA \\
4 & 37 & - & Normal & - & - & Normal & NA \\
5 & NA & - & Low & aCL & Anti-Sm & TM & WBC 16 \\
& & & & & & & Protein 91 \\
6 & 32 & + & Low & - & - & Normal & WBC 40 \\
& & & & & & & Protein 91 \\
7 & 36 & - & Normal & LAC & - & Normal & WBC 141 \\
& & & & & & Protein 96 \\
8 & 52 & + & Normal & NA & - & NM & NA \\
9 & 11 & - & Low & NA & - & Normal & NA \\
10 & 34 & + & Normal & NA & - & NA & Normal \\
11 & 15 & - & Low & aCL & - & Normal & Normal \\
12 & 120 & + & Low & aCL & - & TM & NA \\
13 & 60 & + & Low & aCL & - & TM & NA \\
14 & 19 & + & Low & aCL & - & TM & NA \\
\hline
\end{tabular}

patients, TM presented either as the initial manifestation of SLE or within five years of the diagnosis of SLE. In our patients, nine (64\%) of the patients already had a diagnosis of SLE before the first episode of TM compared with $54(54 \%)$ in the total patient population. Seventy nine per cent of the total patient population had only one episode of TM during the period of observation, $14 \%$ of patients had two episodes and $7 \%$ had more than two episodes.

The clinical and laboratory features of our patients are shown in tables 2 and 3, respectively. Most of our patients had a detectable sensory deficit at the thoracic level with T7 being the most common. Three patients (patients 1, 3 and 11) did not present with a level of sensory deficit. It is of interest to note that the MRI of patient 1 was consistent with TM although a sensory level was not detectable. The most common levels of involvement in the total population were T5-T8.

It has been postulated that patients with TM frequently suffer from other neurological manifestations of SLE. ${ }^{10}{ }^{37}$ Three $(21 \%)$ of our patients also suffered from optic neuritis. This number is lower that that in the total patient population, where $27(48 \%)$ of TM patients also had optic neuritis. Unfortunately in only 55 of the 105 cases was the subject of optic neuritis considered. Although cranial neuropathies are present in $3-16 \%$ of SLE patients, the exact incidence of optic neuritis is unknown but it probably is much less frequent than in patients with SLE and TM. Other neurological manifestations in our patients included psychosis/depression (three patients), cerebrovascular accident (two patients), seizures (one patient) and pseudotumour cerebri (one patient).

Several reports indicate that there is a significant association of TM and the presence of antiphospholipid antibodies (aPL). ${ }^{19} 263841$ In our patients, six of 11 patients $(55 \%)$ tested were positive for either anticardiolipin antibodies (aCL) or lupus anticoagulant (LAC). In only 64 of the 105 total patient population were data on aPL available. Forty one (64\%) of these 64 patients had aPL present during their episodes of TM. The prevalence of aPL in SLE (including asymptomatic patients) is approximately $30-50 \%{ }^{42}$ The incidence of aPL in SLE patients with TM is somewhat higher than that in the general SLE patient population.

MRI is considered the diagnostic method of choice to confirm TM. ${ }^{18}{ }^{43} 44$ MRI results were 


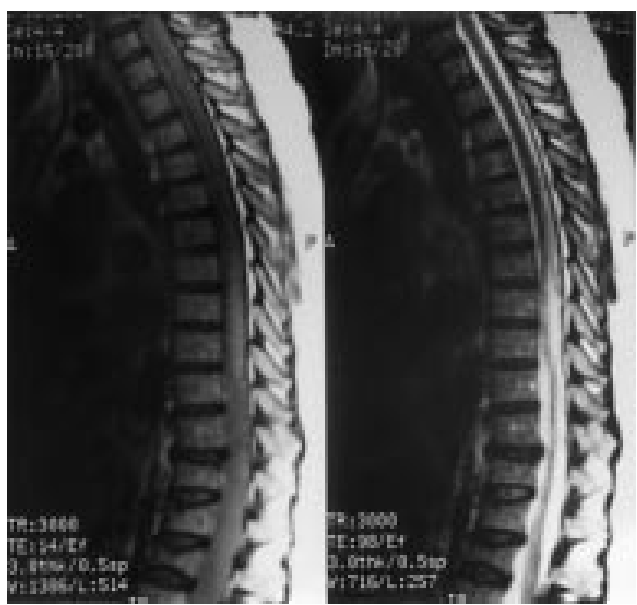

Figure 1 MRI from one of our patients (patient 2) showing increased signal intensity of the mid to lower thoracic spinal cord and atrophy (attenuation) of the spinal cord.

available in 55 of the 105 total patient population. Seven $(54 \%)$ of our patients had a MRI consistent with TM, while $39(70 \%)$ of all 55 patients had abnormal MRI findings. Figure 1 shows a representative MRI (from patient 2)

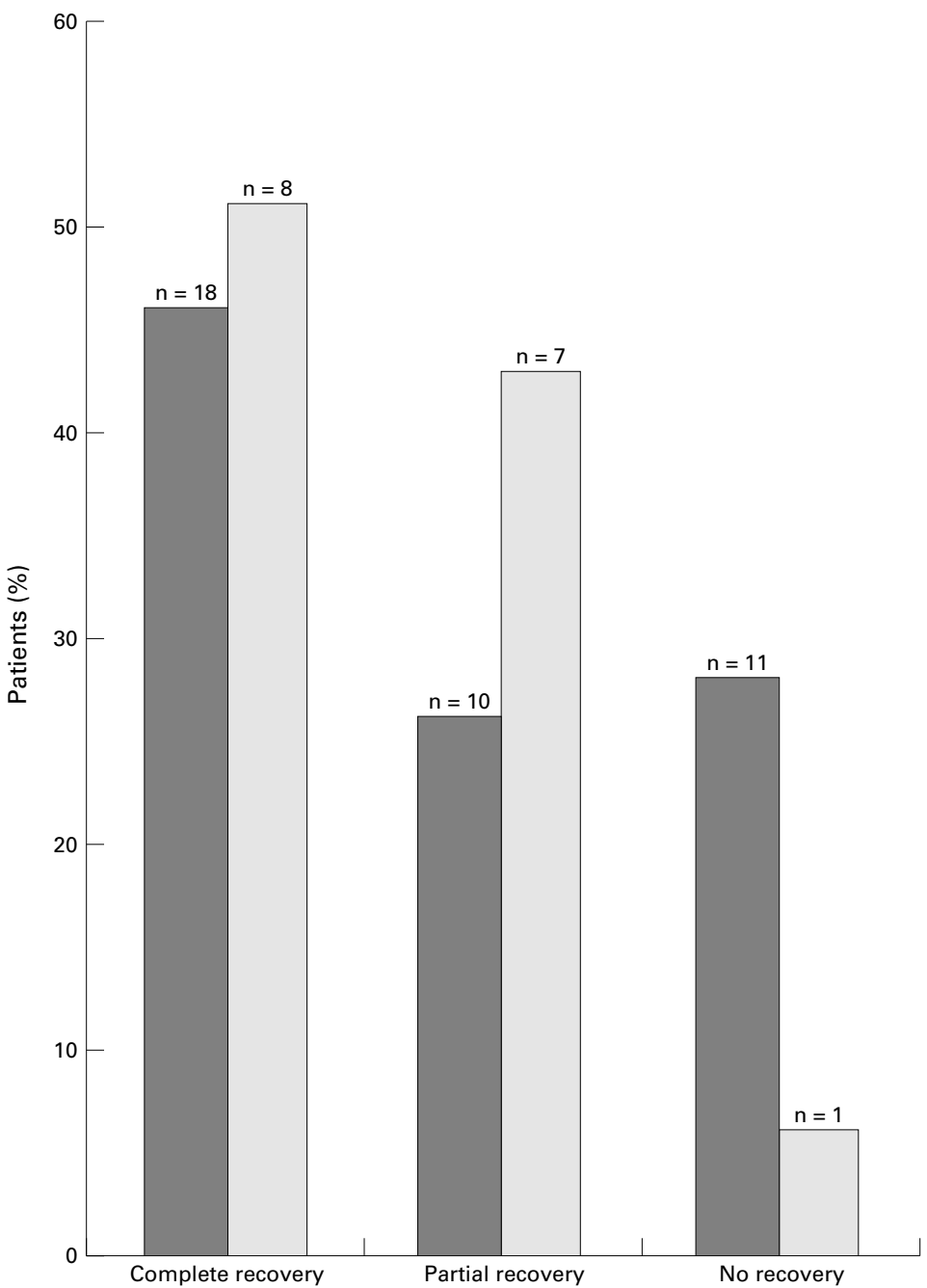

Figure 2 MRI results compared with outcome. Data from patients with an abnormal MRI ( $n=39)$ are shown in black columns, those of patients with a normal MRI $(n=16)$ in gray columns. with increased signal intensity of the mid to lower thoracic spinal cord and atrophy (attenuation) of the spinal cord. We attempted to correlate patient outcome with MRI findings in the total patient population (fig 2). Complete resolution occurred at approximately the same frequency in patients with abnormal MRI (46 $\%$ ) and normal MRI (51\%). However, $28 \%$ of the patients with an abnormal MRI remained paraplegic whereas only $6 \%$ of the patients with a normal MRI remained paraplegic. This indicates that more patients with an abnormal MRI had an unfavourable outcome.

In our patients only three $(22 \%)$ patients had complete resolution of their symptoms whereas nine $(64 \%)$ patients remained unchanged and two $(14 \%)$ patients had partial recovery (table 4). However, the overall outcome in the total patient population with SLE and TM was more favourable. Of these 105 patients, outcome data were available in 86 cases. In one study, ${ }^{19}$ treatment and outcome were not considered and several other patients died early in the course of the disease. Complete recovery occurred in $50 \%$, partial recovery in $29 \%$ and no improvement or deterioration was observed in $21 \%$.

As TM in SLE is a very rare manifestation, treatment guidelines for this entity have not been developed. In the older studies, ${ }^{9}{ }^{12} 15$ most patients were treated with intravenous corticosteroids alone, whereas more recently some centres prefer a more aggressive approach with intravenous corticosteroids plus intravenous $\mathrm{CP}^{21} 324546$ Plasmapheresis has been used to complement this treatment regimen, ${ }^{25}$ and it was also performed on some of our patients. It is difficult to draw conclusions on the different forms of treatment for TM from literature reports presented over a long time span. We therefore attempted to identify tendencies with regards to outcome for different treatment regimens. We observed that treatment with intravenous MP alone led to significant recovery. The use of intravenous MP followed by intravenous CP seemed to be more effective than intravenous MP alone. Additional treatment with plasmapheresis in patients that did not improve with intravenous $\mathrm{MP}$ and intravenous $\mathrm{CP}$ did not seem to improve outcome further. No unusual features could be identified in the patients who did not respond to treatment.

It would be of interest to correlate the activity of SLE at onset of TM with the patients' outcome. Unfortunately, the calculation of the SLAM from the cases derived from the literature was not possible because of the lack of important clinical data. In our patient group, patients with a higher SLAM score were generally treated more aggressively (table 4). However, more aggressive treatment was not associated with better clinical outcome, as all patients in treatment group $\mathrm{C}$ remained paraplegic.

\section{Discussion}

TM is a rare, but serious complication of SLE. Previous reports indicated a prevalence of about $1-2 \%{ }^{1}$ This was confirmed in our patient population where TM occurred in about $2 \%$ of patients. This paper is the first 
Table 4 Disease activity, treatment and outcome of our patients with SLE and TM

\begin{tabular}{|c|c|c|c|c|}
\hline Patient & SLAM Score & Treatment & Follow up & Outcome \\
\hline 1 & 15 & $\begin{array}{l}\text { iv MP } \\
\text { plasmapheresis } \\
\text { iv CP }\end{array}$ & 3 years & Paraplegia \\
\hline 2 & 7 & $\begin{array}{l}\text { iv MP } \\
\text { plasmapheresis } \\
\text { iv CP }\end{array}$ & 6 years & Paraplegia \\
\hline 3 & 10 & iv $\mathrm{MP}$, iv $\mathrm{CP}$ & 7 years & Improved R LE paresis \\
\hline 4 & 6 & iv MP & 4 years & Improved, paresthesias \\
\hline 5 & 23 & $\begin{array}{l}\text { iv MP } \\
\text { plasmapheresis } \\
\text { iv CP }\end{array}$ & 5 years & Paraplegia \\
\hline 6 & 9 & iv $M P$, iv $\mathrm{CP}$ & 13 years & Paresthesias, sensory loss \\
\hline 7 & 12 & iv $M P$ & 9 years & Paraplegia \\
\hline 8 & 3 & $\begin{array}{l}\text { iv MP } \\
\text { plasmapheresis } \\
\text { iv CP }\end{array}$ & 6 years & Paresthesias, paraparesis \\
\hline 9 & 3 & iv MP & 14 years & Recovered \\
\hline 10 & 12 & iv MP & 22 years & Paraplegia \\
\hline 11 & 14 & iv $\mathrm{MP}$, iv CP & 10 years & $\begin{array}{l}\text { Paraparesis, neurogenic } \\
\text { bladder }\end{array}$ \\
\hline 12 & 12 & iv $\mathrm{MP}$, iv $\mathrm{CP}$ & 2 years & $\begin{array}{l}\text { Paraparesis, neurogenic } \\
\text { bladder }\end{array}$ \\
\hline 13 & 8 & iv $\mathrm{MP}$, iv $\mathrm{CP}$ & 1 year & Paraplegic \\
\hline 14 & 12 & iv $\mathrm{MP}$ & 6 months & Improved, sensory loss \\
\hline
\end{tabular}

attempt to analyse all cases of TM in patients with SLE published in the literature. We include the presentation of TM in 14 patients with SLE from two academic centres as well as 91 cases reported in the published literature.

There have been conflicting data in the literature about the timing of TM compared with the onset of SLE. From our study, TM occurring as the initial manifestation of SLE is rather common (39\% of the total patient population). In $42 \%$ of the total patient population analysed, TM presented within the first five years of a diagnosis with SLE. The prominent presentation of TM in SLE seems to be a sensory level, predominantly in the thoracic area.

Surprisingly, the outcome of TM in SLE in the total patient population was favourable. This is in contrast with several reports, ${ }^{8} 304347$ including our own patients where the overall outcome was generally unfavourable. It has been postulated $^{30}$ that aggressive treatment early in the course of the disease is crucial for a favourable response. This could not be confirmed in our patients, where most were treated soon after the onset of symptoms. Furthermore, outcome in general could not be related to disease activity. The evaluation of the total patient population of 105 cases indicates that the clinical manifestations of TM may improve with the use of intravenous $M P$, but that results are even more favourable if intravenous $\mathrm{MP}$ is followed by intravenous CP. It is unclear whether plasmapheresis has any additional therapeutic benefit. In our patients, those with higher SLE disease activity were treated with a more aggressive regimen. This, however, was not associated with a better outcome. As there are no therapeutic guidelines for TM in SLE, clinicians are probably inclined to use more aggressive treatment in patients that present with severe neurological deficits and multisystem disease. It remains to be seen whether plasmapheresis has any role in the treatment of TM in the future.

It is of interest that the prevalence of aPL seems to be higher in SLE patients with TM compared with SLE patients in general. Lavalle et $a l^{19}$ report 10 of 11 patients with TM and
SLE as having aPL. Of the 64 out of a total of 105 patients tested for aPL, $64 \%$ of all patients tested were positive for aPL. This might be important for the aetiology of TM, as spinal cord necrosis secondary to arterial thrombosis might be a pathological factor. Unfortunately, necropsy material from patients with TM and SLE is limited. In two studies, ${ }^{8} 9$ necrosis of the spinal cord was present at necropsy, but thrombosis of the spinal vessels was not seen. A spinal vessel thrombosis might explain the predominance of TM in the thoracic spine. The blood supply of the spinal cord relies on three vessels: the anterior median longitudinal arterial trunk and a pair of posterolateral trunks near the posterior nerve rootlets. The longitudinal arterial trunks are largest in the cervical and lumbar regions and are much smaller in the thoracic region. If there were vascular compromise secondary to thrombosis, the thoracic cord would be most vulnerable because of the limited blood supply. The early use of anticoagulation in these patients might be important for the outcome of the disease. This aspect of TM in SLE has not been studied. We identified six patients with either LAC or aCL in our patients. Only two of these patients (patients 7 and 11 , respectively), were treated with anticoagulation before the onset of TM. Both patients remained paraplegic. Three more patients received anticoagulation once their LAC/aCL status was known. Of these, two remained paraplegic and one had a residual sensory deficit. Furthermore, only aCL and LAC are routinely studied in SLE patients. It is possible that other antibodies with hypercoagulable properties that are not routinely tested, play a part in the disease process. Recently, anti-annexin $\mathrm{V}^{48}$ anti-activated protein $\mathrm{C}^{49}$ and anti-oxidised low density lipoprotein antibodies ${ }^{50}$ have been associated with arterial and venous thrombosis.

Also of interest is the association of optic neuritis with TM in patients with SLE. The association of TM and optic neuritis was first described by Devic in $1894 .{ }^{51}$ It has been postulated that optic neuritis in SLE is associated with aPL. ${ }^{26}$ In our patients, there was no association of aPL with optic neuritis or any other neurological manifestations.

In summary, we have provided the clinical features, treatment and outcome of 14 cases of SLE related TM as well as the review of 91 additional cases previously described in the literature. Although we attempted to report as completely as possible on the 105 cases that were available for review, important data were often not available in the literature reports. This pertains especially to the disease activity of SLE. Our references date back to 1972, when certain diagnostic studies (for example, MRI, antiphospholipid antibody tests) or treatment options (for example, intravenous CP) were not available. Furthermore, there are several studies in the non-English literature that could not be included in our review. While the overall outcome of TM in SLE seems to be better than previously thought, the optimal treatment regimen of this condition is not certain although patients seem to benefit from intravenous CP in 
addition to intravenous MP with tapering doses or oral corticosteroids. Controlled studies and perhaps the creation of a registry for SLE patients with TM could help to develop an effective treatment strategy and shed more light on this rare but serious condition.

We thank Dr Ioannis Tassiulas for a critical review of the manuscript.

Funding: this work was supported in part by the Lupus Foundation of Philadelphia, the Gilbert Memorial Trust and the Pearl Lisker Memorial Research Foundation.

1 West SG. Neuropsychiatric lupus. Rheum Dis Clin North Am. 1994;20:129-58.

2 West SG. Lupus and the central nervous system. Curr Opin Rheumatol 1996;8:408-14.

3 Berman M, Feldman S, Alter M, Zilber N, Kahana E. Acute transverse myeltitis: Incidence and etiologic considerations. Neurology. 1981;31:966-71.

4 Allen IV, Millar JHD, Kirk J, Shillington RKA. Systemic lupus erythematosus clinically resembling multiple
sclerosis and with unusual pathological and ultrastructural features. J Neurol Neurosurg Psychiatry 1979;42:392401 .

5 Tan EM, Cohen AS, Fries JF, Masi AT, McShane DJ, Rothfield NF, et al. The 1982 revised criteria for the classification of systemic lupus erythematosus. Arthritis Rheum tion of systemic

6 Liang MH, Socher SA, Larson MG, Schur PH. Reliability and validity of six systems for the clinical assessment of disease activity in systemic lupus erythematosus. Arthritis Rheum 1989;32:1107-18.

7 Andrianakos AA, Duffy J, Suzuki M, Sharp JT. Transverse myelopathy in systemic lupus erythematosus. Report of three cases and review of the literature. Ann Intern Med $1975 ; 83: 616-24$

8 April RS, Vansonnenberg E. A case of neuromyelitis optica (Devic's syndrome) in systemic lupus erythematosus. Neurology $1976 ; 26: 1066-70$.

9 Kinney E, Berdoff RL, Nagbushan SR, Fox LM. Devic's syndrome and systemic lupus erythematosus. A case report syndrome and systemic lupus erythematosus.

10 Warren RW, Kredich DW. Transverse myelitis and acute central nervous system manifestations of systemic lupus

11 Hardie KJ, Isenberg DA. Tetraplegia as a presenting feature of systemic lupus erythematosus complicated by pulmonary hypertension. Ann Rheum Dis 1985;44:491-3.

12 Zerbini CA, Fidelix TS, Rabello GD. Recovery from transverse myelitis of systemic lupus erythematosus with steroid therapy [letter]. J Neurol. 1986;233:188-9.

13 Jabs DA, Miller NR, Newman SA, Johnson MA, Stevens MB. Optic neuropathy in systemic lupus erythematosus. Arch Ophthalmol 1986;104:564-86.

14 de Brum-Fernandes AJ, Lucena-Fernandes MF, Levy Neto M, Cossermelli W. Myelitis in systemic lupus erythematosus [letter]. Arthritis Rheum 1987;30:238-9.

15 Sands ML, Ryczak M, Brown RB. Recurrent aseptic meningitis followed by transverse myelitis as a presentation of gitis followed by transverse myelitis as a presentation of
systemic lupus erythematosus. J Rheumatol 1988;15: systemic

16 Marabani M, Zoma A, Hadley D, Sturrock RD. Transverse myelitis occurring during pregnancy in a patient with systemic lupus erythematosus. Ann Rheum Dis 1989;48: $160-2$

17 Propper DJ, Bucknall RC. Acute transverse myelopathy complicating systemic lupus erythematosus. Ann Rheum Dis. 1989;48:512-15.

18 Boumpas DT, Patronas NJ, Dalakas MC, Hakim CA, Klippel $\mathrm{JH}$, Balow JE. Acute transverse myelitis in systemic lupus erythematosus: magnetic resonance imaging an review of the literature. J Rheumatol 1990;17:89-92.

19 Lavalle C, Pizarro S, Drenkard C, Sanchez-Guerrero J, Alarcon-Segovia D. Transverse myelitis: a manifestation of systemic lupus erythematosus strongly associated with antiphospholipid antibodies [see comments]. J Rheumatol 1990;17:34-7.

20 Misteli M, Conen D. [Acute transverse myelitis in systemic lupus erythematosus: successful therapy with cyclophosphamide and prednisone]. Schweiz Med Wochensch

21 Barile L, Lavalle C. Transverse myelitis in systemic lupus erythematosus-the effect of IV pulse methylprednisolone and cyclophosphamide. J Rheumatol 1992;19:370-2 .

22 Simeon-Aznar CP, Tolosa-Vilella C, Cuenca-Luque R, Jordana-Comajuncosa R, Ordi-Ros J, Bosch-Gil JA. Transverse myelitis in systemic lupus erythematosus: two cases with magnetic resonance imaging. $\mathrm{Br} \mathrm{J}$ Rheumatol 1992;31:555-8.

23 Tola MR, Granieri E, Caniatti L, Paolino E, Monetti C, Dovigo L, et al. Systemic lupus erythematosus presenting with neurological disorders. J Neurol 1992;239:61-4.

24 Szer IS, Miller JH, Rawlings D, Shaham B, Bernstien B. Cerebral perfusion abnormalities in children with central nervous system manifestations of lupus detected by single photon emission computed tomography. J Rheumato
25 Klaiman MD, Miller SD. Transverse myelitis complicating systemic lupus erythematosus: treatment including hydroxychloroquine. 1993;72:158-61.

26 Cordeiro MF, Lloyd ME, Spalton DJ, Hughes GR. Ischaemic optic neuropathy, transverse myelitis, and epilepsy in an anti-phospholipid positive patient with systemic lupus erythematosus [letter]. J Neurol Neurosurg Psychiatry 1994;57:1142-3.

27 Salmaggi A, Lamperti E, Eoli M, Venegoni E, Bruzzone MG, Riccio G, et al. Spinal cord involvement and systemic lupus erythematosus: clinical and magnetic resonance findings in 5 patients [published erratum appears in Clin Exp Rheumatol 1994;12:695]. Clin Exp Rheumatol 1994;12: 389-94.

28 Kira J, Goto I. Recurrent opticomyelitis associated with anti-DNA antibody. J Neurol Neurosurg Psychiatry 1994; $57: 1124-5$.

29 Valesini G, Priori R, Francia A, Balestrieri G, Tincani A, Airo $\mathrm{P}$, et al. Central nervous system involvement in systemic lupus erythematosus: a new therapeutic approach with intrathecal dexamethasone and methotrexate. Springer Semin Immunopathol 1994;16:313-21.

30 Harisdangkul V, Doorenbos D, Subramony SH. Lupus transverse myelopathy: better outcome with early recognition and aggressive high-dose intravenous corticosteroid pulse treatment. J Neurol 1995;242:326-31.

31 Neuwelt CM, Lacks S, Kaye BR, Ellman JB, Borenstein DG. Role of intravenous cyclophosphamide in the treatment of severe neuropsychiatric systemic lupus erythematosus. Am J Med 1995;98:32-41.

32 Baca V, Sanchez-Vaca G, Martinez-Muniz I, RamirezLacayo M, Lavalle C. Successful treatment of transverse myelitis in a child with systemic lupus erythematosus. Neuropediatrics 1996;27:42-4.

33 Chan KF, Boey ML. Transverse myelopathy in SLE: clinical features and functional outcomes. Lupus 1996;5:294-9.

34 O'Riordan JI, Gallagher HL, Thompson AJ, Howard RS, Kingsley DPE, Thompson EJ, et al. Clinical, CSF, and MRI finding in Devic's neuromyelitis optica. J Neurol Neurosurg Psychiatry 1996;60:382-7.

35 Radis CD, Callis KP. Systemic lupus erythematosus with membranous glomerulonephritis and transverse myelitis associated with anabolic steroid use. Arthritis Rheum 1997;40:1899-902.

36 Sanchez-Rodriguez A, Oterino JAM, Hernandez PA. Lupus Myelitis. Arch Intern Med 1998;158:2267-8.

37 Mok CC, Lau CS, Chan EY, Wong RW. Acute transverse myelopathy in systemic lupus erythematosus: clinical presenta-
tion, treatment, and outcome. J Rheumatol 1998;25:467-73.

38 Schantz V, Oestergaard LL, Junker P. Shrinking spinal cord following transverse myelopathy in a patient with systemic lupus erythematosus and the phospholipid antibody lupus erythematosus and the phosph

39 Deodhar AA, Hochenedel T, Bennett RM. Longitudinal involvement of the spinal cord in a patient with lupus related transverse myelitis. J Rheumatol 1999;26:446-9.

40 Gibson TP, Dibona GF. Use of the American Rheumatism Association's preliminary criteria for the classification of systemic lupus erythematosus. Ann Intern Med 1972;77: $754-6$.

41 Smyth AE, Bruce IN, McMillan SA, Bell AL. Transverse myelitis: a complication of systemic lupus erythematosus that is associated with the antiphospholipid syndrome. Ulster Med J. 1996;65:91-4.

42 Alarcon-Segovia D, Deleze M, Oria CV, Sanchez-Guerrero J, Gomez-Pacheco L, Cabiedes J, et al. Antiphospholipid antibodies and the antiphospholipid syndrome in systemic lupus erythematosus. A prospective analysis of 500 consecutive patients. Medicine (Baltimore) 1989;68:353-65.

43 Kenik JG, Krohn K, Kelly RB, Bierman M, Hammeke MD, Hurley JA. Transverse myelitis and optic neuritis in systemic lupus erythematosus: a case report with magnetic resonance imaging findings. Arthritis Rheum 1987;30:947-50.

44 Tartaglino LM, Croul SE, Flanders AE, Sweeney JD, Schwartzman RJ, Liem M, et al. Idiopathic acute transverse myelitis: MR imaging findings. Radiology 1996;201:661-9. 5 Baca V, Lavalle C, Garcia R, Catalan T, Sauceda JM, Sanchez $\mathrm{G}$, et al. Favorable response to intravenous methylprednisolone and cyclophosphamide in children with seve

46 Berlanga B, Rubio FR, Moga I, Pac V. Response to intravenous cyclophosphamide treatment in lupus myelopathy nous cyclophosphamide treatment in

47 Tola MR, Casetta I, Granieri E, Caniatti LM, Monetti VC, Pascarella R. Systemic lupus erythematosus related recurrent transverse myelitis in a patient with myasthenia gravis and multiple sclerosis. Eur Neurol 1996;36:327-8.

48 Satoh A, Suzuki K, Takayama E, Kojima K, Hidaka T, Kawakami M, et al. Detection of anti-annexin IV and V antibodies in patients with antiphospholipid syndrome and systemic lupus erythematosus. J Rheumatol 1999;26: 1715-20.

49 Zivelin A., Gitel S, Griffin JH, Xu X, Fernandez JA, Martinowitz $\mathrm{U}$, et al. Extensive venous and arterial thrombosis associated with an inhibitor ot activated protein C. Blood 1999;94:895-901.

50 Cuadrado MJ, Tinahones F, Camps MT, De Ramon E, Gomez-Zumaquero JM, Mujic F, et al. Antiphospholipid, anti- $\beta 2$-glycoprotien-I and anti-oxidized-low-densitylipoprotein antibodies in antiphospholipid syndrome. Q J Med 1998;91:619-26.

51 Devic E. Myelite subaigue compliquee de nevrite optique. Bull Med 1894;8:1033-4. 